Volume 7

Issue 3 May

Article 3

May 1980

\title{
The Public and Care by Non-Physicians: Health Policy \\ Consideration
}

Bebe F. Lavin

Kent State University

Follow this and additional works at: https://scholarworks.wmich.edu/jssw

Part of the Health Policy Commons, and the Social Work Commons

\section{Recommended Citation}

Lavin, Bebe F. (1980) "The Public and Care by Non-Physicians: Health Policy Consideration," The Journal of Sociology \& Social Welfare: Vol. 7 : Iss. 3 , Article 3.

Available at: https://scholarworks.wmich.edu/jssw/vol7/iss3/3

This Article is brought to you by the Western Michigan University School of Social Work. For more information, please contact wmu-scholarworks@wmich.edu.

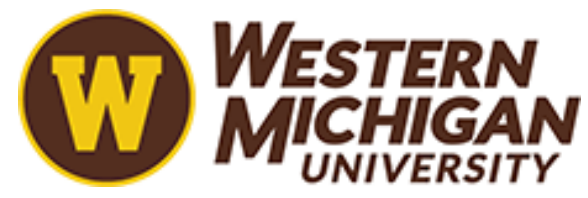


THE PUBLIC AND CARE BY NON-PHYSICIANS: HEALTH POLICY CONSIDERATION*

Bebe F. Lavin, Kent State University

In an effort to resolve what some define as a crisis in health care, medical paraprofessionals have become an increasing part of the primary care scene. As the training and use of paraprofessionals expands there has been growing insistence that much of what office-based physicians do could be handled as well or better by these non-physicians. If it is health policy to encourage the use of paraprofessionals to alleviate the shortages and maldistribution of primary care doctors, acceptance of these personnel by the public is a critical issue.

A study of the public in a Midwest area suggests considerable variability in willingness to accept a trained person other than a doctor to do several tasks usually considered within the domain of the physician. The findings show that the typical demographic and attitudinal variables do little to explain differences in public willingness to accept paraprofessionals. However, the context in which service is delivered is suggested as a possible explanation of acceptance. Several policy relevant issues are discussed, including the need to provide settings for medical care that will maximize public willingness to be treated by non-physicians.

One solution to what some have defined as the crisis in the delivery of health care in the United States has been the redefinition and reallocation of tasks among the providers of primary care. Non-physician personnel are trained increasingly to handle many of the wide range of problems now presented to primary care doctors. In particular persons titled nurse practitioners,

*This research was supported in part by U.S. Public Health Service Grant No. R01-45-0849, Nationa1 Center for Health Services Research. I acknowledge with gratitude the help of Marie Haug with this study and also thank those colleagues who commented on an earlier draft of this article when presented at the annual meeting of the Society for the Study of Social Problems, Boston, 1979. 
physicians' assistants, nurse extenders, or ancillary health workers are expected to act in concert with physicians to provide the basic health and illness care needed by the vast majority of people who seek medical attention.

It has been estimated that 60 percent of patient visits to physicians are for general or primary care (Rogers, 1977), while perhaps 75 to 80 percent of all requests made in primary care settings could be taken care of by the appropriately trained nurse practitioner (Mauksh, 1978). Cohen (Cohen et a1., 1974) suggests that at least 66 percent of the patients seen by midlevel practitioners can be managed with no consultation with physicians. Although there is nothing extraordinary about doctors' use of personnel to assist in the varied tasks of their practice, the different and current implication is that much of what office-based primary care physicians do could be handled as well as or better by a non-physician. A recent article in a well-known medical journal establishes this theme in the title by asking, "Does the Practice of Medicine Require a Medical Degree?" (Sox, 1978).

The issue of the expanded use of non-physicians in primary care is raised in several contexts. For example, use of such manpower is a means to alleviate the perceived maldistribution and/or shortage of primary care doctors (Eisenberg, 1977; Rogers, 1977). Moreover, it affords economies by making better use of the time of a high priced commodity, the physician (Margulies, 1975, Nelson et al., 1975). Further, it is suggested that expansion in knowledge and technology, along with the need to integrate the varied and often non-medical problems that patients bring to physicians, require specialization and a new division of labor (Bates, 1970; Breslau, 1977; Svarstad, 1976; Thomas, 1977).

Although most of the programs for the training and utilization of these midlevel practitioners have been in existence for a relatively short period of time--ten to fifteen years--a growing body of literature has developed. Many of the more recent studies focus on the problems of appropriate role definitions (Barr, 1978; Burkett et a1., 1978, Mauksch and Young, 1974, Merenstein et a1., 1974; Record and Greenlick, 1973) and different patterns of use as related to client characteristics (Duttera and Harlan, 1978; Herman, 1972; Hessel and Haggerty, 1968; Lewis et a1., 1976; Morris and Smith, 1977; Roemer, 1976).

Perhaps the most critical issues, however, have not been adequately addressed. The first is the question of the quality of the care by non-physicians, the second is the willingness of the public to accept such personnel. 
Quality of care is an elusive concept and is difficult to measure (Kissick, 1971). Nevertheless numerous studies have attempted to assess quality of non-physician services. A comprehensive review of this research through 1975 (Celentano, 1978)reveals that the methodologies of this type of research are deficient--a problem noted by others as well (Sox, 1978). In order to accept the findings of studies which conclude that the quality of care by midlevel practitioners is as safe and as effective as the care provided by a physician (Cohen et al., 1974; Tompkins et al., 1977; Sackett et a1., 1974; Spitzer et a1., 1974), one needs to ignore such criticism of methodologies. However, none of this research links the use of paraprofessionals to the twoclass nature of the health care system (Krause, 1977). Some writers have implied that the poor, ghetto residents and rural patients, those most often treated by non-physicians, could be receiving second class medical treatment or at least they may view it as such (Rushing and Miles, 1977).

This leads to the second major question. What is the degree to which the public is willing to accept the non-physician in lieu of the doctor? The answers to this are few, and do not reflect consensus because they are of ten based on anecdotal studies of limited generalizability (Pickard, 1976). For example, some studies report that patient acceptance of non-physicians and patient satisfaction with care is at a high level (Breslau, 1977; Greenfield et al., 1975; Lewis, 1971; Linn, 1975; Pondy, 1970). Yet, Andersen (1971) found the public is reluctant to allow nonphysicians to do some common and not technically difficult medical tasks.

An opportunity to examine public response to non-physicians became available in connection with a study primarily concerned with the examination of the authority relationship between physicians and the public (Haug and Lavin, 1977). The data collected in that study allowed assessment of the degree to which the public is willing to accept the use of trained persons other than a physician to perform certain patient care tasks which are ordinarily considered the domain of the physician. Further, the data explored demographic and attitudinal factors which might explain differences in acceptance.

\section{Study Setting and Methods}

The data reported here are based on a survey of the public, using a randomly selected sample from three different sized Midwest communities during Spring, 1976. Person-to-person inter- 
views lasting nearly an hour were conducted by trained interviewers. A response rate of 82 percent yielded 640 cases for analysis. As compared with census data on the total population, older and better educated persons are somewhat over-represented, but in general the study sample is typical of the American public.

In order to measure acceptance of paraprofessionals, the public sampled was asked how willing they would be to let some trained person other than a doctor do the following tasks:
1) give shots;
2) advise on routine problems;
3) do a routine physical exam;
4) deliver babies;
5) prescribe medicines;
6) remove tonsils.

The items are presented here in the order which emerged in a Guttman analysis, rather than the order used in the interview. Although the Guttman analysis (Nie et a1., 1975) did not quite reach acceptable scalability criteria (coefficient of reproducibility of .87 and coefficient of scalability of .55), it was useful in drawing attention to the order of "difficulty" in accepting the items. Thus 84 percent of the respondents would be willing to have non-physicians give shots, and almost 60 percent would accept advice on routine problems or allow a paraprofessional to do a routine physical. Nearly half would be willing to use a nonphysician to deliver a baby. However only about 16 percent would allow trained paraprofessionals to prescribe medicine or remove tonsils.

For the purposes of this report a summated index of Acceptance of Medical Paraprofessionals was used. A rejection of any item was scored as one, a qualified yes as two, and an unqualified yes as three. The summated total was then divided by the number of items answered. In effect this meant that if any items were not answered, a score was equal to the mean of the other answers of that respondent. To avoid fractional numbers, all were multiplied by ten. Thus the dependent variable, Acceptance of Medical Paraprofessionals, had a theoretical range of ten to 30 , with the higher score indicative of higher acceptance.

Certain variables seem likely to affect public willingness to accept other than a doctor to do certain tasks and therefore are included as explanatory. The authority of physicians, and thereby the legitimation of the definition of the tasks they consider a part of their role, rests in the expectation that they have greater knowledge and expertise than do other health person- 
nel or patients. Also, their authority derives from the expectation that their overriding concern is for what is best for their patients (Parsons, 1951, 1975; Gill, 1978). It could then be anticipated that to the degree that the public is knowledgeable about health matters or to the extent that they doubt the expertise or the concern of the physician, legitimation of the authority of the physician will be called into question. This, in turn, will increase the likelihood for the acceptance of others in the doctor's role. Accordingly, level of health knowledge is introduced as a major explanatory variable, along with five psychosocial variables that were expected to indicate the public's attitudes about either medicine in general or doctors in particular.

A scale measuring skepticism of medicine and of doctors developed in earlier research (Suchman, 1965), indicates whether respondents doubt the efficacy of medicine or the ability of doctors to cure their ills. The belief in physicians' competence or the belief in doctors' personal concern for patients was assessed by the scale created originally by Zyzanski and colleagues (Zyzanski et a1., 1974). Finally a measure of willingness to question doctors' authority was developed from the Adorno F-Scale (Robinson and Shaver, 1973). 1 For each of these attitude variables, in which the direction suggested less belief in either medicine or doctors or in which questions were raised as to the physician's authority in medical encounters, it was anticipated that there would be greater willingness to accept trained non-physicians.

The demographic characteristics of age and social class are included not only because they may reflect differences in levels of education but also because younger, middle class, and by implication better educated, persons could be expected to take a more challenging attitude toward physicians (Haug and Lavin, 1978). Moreover, good health and little experience with doctors and medical settings were expected to indicate low dependency on physicians and therefore greater acceptance of the use of non-physicians. Race, sex, and level of urbanization were other demographic variables included since their effects on other health behaviors have been previously noted. For purposes of analysis, level of knowledge is also considered a demographic characteristic.

1 For further description of this variable, see Haug and Lavin (1978). 


\section{Findings}

The findings reveal considerable variability in this public's willingness to accept a trained person other than a doctor to do the several tasks suggested (Table 1). When scores are grouped,

\section{Table 1}

Willingness to Accept Medical Paraprofessionals (percents)

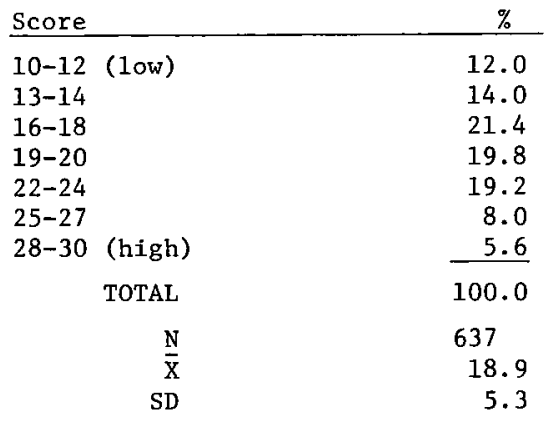

the distribution approaches the normal, with a mean of nearly 19 , and a standard deviation of five. But it must be noted that about 26 percent reject allocating most of these tasks to paraprofessionals, while less than 14 percent are in the two highest categories, indicating that few accept the use of non-physicians for all or nearly all of these health care activities.

In order to evaluate to what extent any of the demographic or attitudinal variables could explain the differences found in Acceptance of Medical Paraprofessionals, zero-order correlations and stepwise multiple regressions were calculated. Four of the demographic variables--health knowledge, age, sex, and social class, and two of the attitudes--belief in physician competence and a questioning of physician authority, are statistically significant at the zero-order level. This finding indicates that the relationship of these variables to Acceptance of Medical Paraprofessionals is not due to sampling error (Table 2, column A). Those respondents with greater health knowledge, younger, male, or of higher social class were more likely to show a greater willingness to accept non-physicians. However the correlations are substantively smal1. Health knowledge, the most important variable, explains only a little over five percent of the variance. At the social psychological level, those willing to question the 
Table 2

Relationship of Selected Demographic and Social Psychological Variables to Willingness to Accept Medical Paraprofessionals

$$
\frac{A}{\text { Simple } r} \quad \frac{B^{1}}{\text { Beta }}
$$

Demographic

Health knowledge
Sex
Family Social Class
Age
Race
Level of Urbanization
Health status
Medical experience
ocial Psychological

Belief in doctor competence Questioning doctor authority

Belief in doctor concern

*statistically significant at .05 level or better

B refers to standardized regression coefficients, beta, and are reported only if they met the $F$ or tolerance level $(\mathrm{F}=1.5, \mathrm{~T}=.50)$.

doctor's authority were willing to accept "surrogate" doctors. Contrary to expectations, those with a high belief in doctors' competency were also willing to accept such care. Both of these correlations were at statistically significant but substantively trivial levels.

In the stepwise multiple regression, all the theoretically meaningful variables were entered into the same equation whether or not they were statistically significant at the zero order leve1. This procedure reveals the impact of each of the explanatory variables on the dependent variable when all others are taken into account and uses beta weights as the criteria for relarive importance. Now only five of the entire set are statistically significant--health knowledge, age, sex, social class, and belief in doctors' competency. Questioning doctors' authority 
does not emerge as occurring beyond chance (Table 2, column B). The most salient variables in the explanation of willingness to accept non-physicians are greater health knowledge (Beta $=.18$ ), being male (Beta $=-.15$ ), believing in physician competence (Beta $=.10$ ), higher social class (Beta $=.09$ ), and younger age (Beta $=-.09)$. Although the coefficient of determination is statistically significant, this variable set explains only 11 percent of the variance, suggesting that other factors are at work.

In order to explore these relationships further, the analysis was repeated for each individual item making up the Acceptance of Medical Paraprofessionals scale. The results reveal two distinctly different patterns (Table 3). One set of four items, (Give Shots, Advise on Routine Problems, Do a Routine Physical Exam, and Deliver Babies) shows a pattern somewhat similar to the total scale. The $\mathrm{R}^{2} \mathrm{~s}$ are not markedly different, ranging from .06 to .13, and except for Advise on Routine Problems, the most important explanatory variables emerging from the stepwise regression continue to be health knowledge and sex. It is noteworthy that these are the same tasks that members of the public might have observed paraprofessionals performing in doctors' offices, clinics or hospitals during previous visits.

Two other items, Prescribe Medicines and Remove Tonsils, are left almost completely unexplained by the independent variables utilized-- $\mathrm{R}^{2}$ is .01 in each case--, and health knowledge disappears from the regression. It is noteworthy in this instance that the two tasks mentioned are not performed currently by paraprofessionals, and are highly unlikely to have been experienced previously by the public. Unfortunately the data are not available for testing the effect on acceptance of past exposure to paraprofessional services.

These findings would generally indicate the advisability of dropping the Prescription and Tonsils items from the scale, and recalculating the regression equations. However, examination of the point-biserial item to total correlations shows that these items have the highest correlation values (.61 and .63) and thus are not candidates for elimination on the basis of usual scale analysis criterion.

Another intriguing finding is that the effect of age is reversed on the Deliver Babies item. Here it is the older rather than the younger respondents who are willing to have a non-physician take this responsibility. Experience could be once again explanatory. older generations may recall a time when midwives, not obstetricians, officiated at births and are comfortable with 


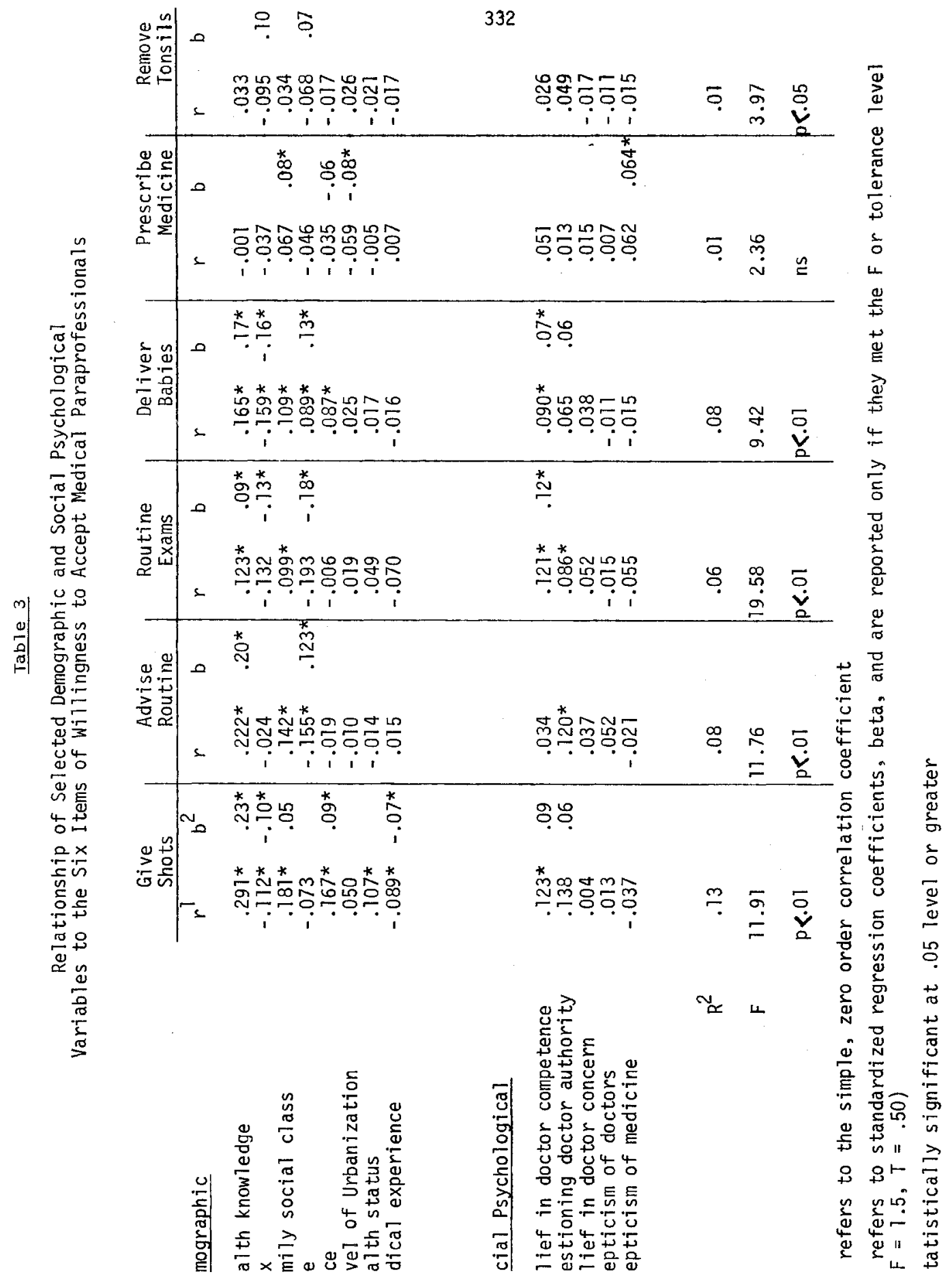


this state of affairs.

In sum, both the total scale and individual item analysis reveal that the postulated array of explanatory variables is incomplete and that other factors need to be identified. The item analysis suggests that at least one of these is past exposure to paraprofessionals at work.

\section{Discussion}

These findings raise a number of difficult questions that have policy implications. First, why do health status, medical experience, and various attitudes about the efficacy of medicine and physicians have so little effect on willingness to use nonphysicians, while belief in doctor's competence is, even if weakly, related? It might be due to a recognition among younger, more knowledgeable, and more middle class persons that most of the tasks involved are really not that complex or life threatening, and are generally done under a doctor's direction. And a competent doctor will monitor that they are done properly. Thus whether one's own health is good or bad, or one's view of medicine and medical care providers is skeptical or not is not as critical in acceptance as being knowledgeable about health matters. From a policy perspective, this suggests that programs of education can increase acceptance of paraprofessional use.

Second, is it likely that those most accepting will be those most apt to utilize paraprofessionals? Since the poor, black, elderly and rural populations suffer most from maldistributions of physicians, and thus are more often treated by paraprofessionals, the groups exposed to this type of care are in fact, found to be the most rejecting or indifferent. Race and level of urbanization were not relevant to acceptance. It was the older and lower social class respondents who were more likely to eschew paraprofessionals as less acceptable, perhaps viewing their use as providing second class care, continuing in a new form the discrimination they have suffered in the past. This suggests extension of policies that press physicians to practice in underserved areas, rather than emphasizing substitute care providers.

Thirdly, what factors are likely to account for the 90 percent or more of unexplained variance in this study? From a policy point of view, this is an important question. Assuming that health provider shortages and maldistributions will continue to be alleviated by training new types of paraprofessional labor, it will be important to uncover factors that encourage public 
acceptance. One factor not evaluated in this study that could be crucial is the degree to which the public accepts care by physicians and non-physicians as equivalent. Two recent studies of public attitude toward physicians' assistants and nurse practitioners indicate that the public does not judge care by non-physicians as equivalent to that of doctors. An important reservation made by these respondents is that such care be supervised by a physician (Litman, 1971: Storms and Fox, 1979). In the research reported in this article the public was asked about their willingness to accept a physician substitute, not an assistant. Findings suggest that their willingness to do so is, at least in part, the result of a realistic evaluation of medical tasks. Therefore, public acceptance of physician substitutes would necessitate reevaluation by the public of tasks customarily performed by physicians and require in many cases, a demystification of these tasks. Such prospects seem unlikely.

Another factor affecting public acceptance of non-physicians might be the response to potentially lower fees being charged by paraprofessionals for the same tasks performed by physicians. It is likely that any differences in fees would be interpreted as indicating a two-tiered system of health care. Those unable to select medical alternatives would then believe that they were in fact receiving second class medical care.

Thus a further question is raised as to the point of intervention in order to encourage broader public willingness to use non-physicians in primary care. Since the standard demographic variables function weakly if at all, while health status and attitudes are generally irrelevant to acceptance, these factors cannot be considered as change agents. As the individual item analysis indicated, the answer may involve differential exposure to the paraprofessionals who give service. However this creates a logical dilemma. If the poor, black, elderly and rural are most apt to be treated by non-physicians, and thus are most experienced with this type of care, why are they not also the most accepting? Could it be that their lack of alternative sources of care forces acceptance as a matter of necessity rather than choice, and creates thereby a sense of deprivation and negative feelings?

In other words, the conditions under which the experience occurs is critical. In the context of superior care, usually the case for patients of higher social class, paraprofessionals are acceptable as physician extenders once their services have been experienced. In the context of episodic and less-superior care, usually the case for disadvantaged patients, paraprofessionals 
are less acceptable as physician substitutes, and may appear to symbolize deprivation. Thus there is an interaction between the experience of paraprofessional care and the quality of the circumstances in which that care is delivered.

Accordingly, from a policy perspective, one might suggest that improving the quality and context of health services are necessary preconditions for extending acceptance of the use of non-physicians in the delivery of medical care. Unfortunately current policy decisions seem to be based on speculation and guesswork about public reaction. This can lead to the creation of more problems than the ones the policy makers are attempting to resolve.

\section{References}

Andersen, Ronald

1971 "The public's view of the crisis in medical care: an impetus for changing delivery systems?" Economic and Business Bulletin 24 (Fal1):44-52.

Barr, Judith $\mathrm{K}$.

1978 "The health associate: definition of a new role." Paper presented at the Eastern Sociological Society, Philadelphia (Apri1).

Bates, Barbara

1970 'Doctor and nurse: changing roles and relations." New England Journal of Medicine. 283:129-134.

Burkett, Gaye L., Margaret Parken-Harris, Joan C. Kuhn and Gerald H. Escovitz

1978 "A comparative study of physicians' and nurses' conceptions of the role of nurse practitioner." American Journal of Public Health 68 (November): 1090-95.

Breslau, Naomi

1977 "The role of the nurse-practitioner in a pediatric team: patient definitions." Medical Care 15 (December) : 1014-23. 
Cohen, E.D., L.M. Crootof, M,G. Goldfarb, K. Keenen, M. Korper and M. Triffin

1974 An Evaluation of Policy Related Research on New and Expanded Roles of Health Workers. New Haven, Conn.: Office of Regional Activities and Continuing Education, Yale University School of Medicine.

Celentano, David D.

1978 "Critical policy issues concerning new health practitioners--quality of care." Sociological Symposium 23 (Summer) :61-77.

Duttera, Julian M. and William R. Harlan

1978 "Evaluation of physician assistants in rural primary care." Archives of Internal Medicine 138 (February): 224-28.

Eisenberg, Leon

1977 "The search for care." Daedalus 106 (Winter):235-45.

Gil1, Derek G.

1978 "Limitation upon choice and constraints over decisionmaking in doctor/patient exchanges." Pp. 141-154 in Eugene Gallagher (ed.) The Doctor-Patient Relationship in the Changing Health Scene: An International Perspective. Washington, D.C.: John E. Fogarty International Center for Advanced Study in the Health Sciences.

Greenfield, S., F.E. Bragg, D.L. McCraith, and J. Blackburn 1975 "Upper-respiratory tract complaint protocol for physician-extenders." Archives of Internal Medicine, 133:294-99.

Haug, Marie and Bebe Lavin

1977 Final Report: Public Challenge to MD Authority.

U.S. Public Health Grant \#1-R01-HS-0849-01.

1978 "Method of payment for medical care and patient attitudes to physician authority." Journal of Health and Social Behavior. 19(September):279-291.

Herman, Mary $w$.

1972 "The Poor: their medical needs and the health services available to them." The Annals (January): $12-21$. 
Hessel, Samuel J. and Robert J. Haggerty

1968 "General pediatrics: a study of practices in the mid-1960's." Journal of Pediatrics 2 (August): 271-79.

Kissick, William L.

1971 "Health manpower in transition." Pp. 162-206 in Ray Elling (ed.) National Health Care: Issues and Problems in Socialized Medicine. New York: AldineAtherton.

Krause, Elliott A.

1977 Power and Illness: The Political Sociology of Health and Medical Care. New York: Elsevier, North Holland, Inc.

Lewis, Charles E.

1971 "The efficiency of new health manpower." A paper presented at the Invitational Health Services Research Conference. Chicago, Illinois (December).

Lewis, Charles E., Rashi Fein, and David Mechanic

1976 A Right to Health. New York: John Wiley and Sons.

Linn, Lawrence S.

1975 "Factors associated with patient evaluation of health care." Health and Society 53:531-548.

Litman, T.J.

1972 "Public perception of the physicians' assistant - a survey of the attitudes and opinions of rural Iowa and Minnesota residents." American Journal of Public Health $62: 343$.

Margulies, H.

1975 Final Report of the Physician Extender Work Group. Washington, D.C.: Health Resource Administration, U.S. Department of Health, Education and Welfare,

Mauksch, Ingebor G.

1978 "The nurse practitioner movement--where does it go from here?" American Journal of Public Health 68 (November) : 1074-75. 
Mauksch, Ingebor G. and P.R. Young

1974 "Nurse-physician interaction in a family medical care center." Nursing Outlook 22:113-119.

Merenstein, J.H., H. Wolfe and K.M. Barker

1974 "The use of nurse practitioners in general practice.' Medical Care 12:445-452.

Morris, Stephen B. and David B. Smith

1977 "The distribution of physician extenders." Medical Care 15(December): 1045-57.

Nelson, E.C., A.R. Jacobs, P.E. Breen and K.G. Johnson

1975 "Impact of physician's assistant on patient visits in ambulatory care practices." Annals of Internal Medicine 82:608-612.

Nie, Norman H., C. Hadlai, Jean Jenkins, Karin Steinbrenner, and Dale Brent

1975 Statistical Package for the Social Sciences, 2nd edition. New York: McGraw-Hill.

Parsons, Talcott

1951 The Social System. Glencoe: Free Press.

1975 "The sick role and the role of the physician reconsidered." Milbank Memorial Fund Quarterly, Health and Society 53:257-278.

Pickard, GIenn C., Jr.

1976 "Midlevel practitioners: nurse practitioners and physicians' assistants." Pp. 129-140 in John Noble (ed.) Primary Care and the Practice of Medicine. Boston: Little, Brown and Company.

Pondy, Louis

1970 A Study of patient acceptance of the physician's assistant." Durham, N.C.: Duke University, GBSA Paper no. 27.

Record, Jane C. and Merwyn R. Greenlick

1973 "New health professionals and physician role: an hypothesis from Kaiser experience." Public Health Reports 90(May): 241-246. 
Robinson, John and Phillip R. Shaver

1973 Measures of Social Psychological Attitudes. Revised Edition. Ann Arbor: Survey Research Center, Institute for Social Research 308-317.

Roemer, Milton I.

1976 Rural Health Care. St. Louis: C.V. Mosby.

Rogers, David E.

1977 "The challenge of primary care." Daedalus 106

(Winter) : 81-105.

Rushing, William A. and David L. Miles

1977 "Physicians, physicians' assistants, and the social characteristics of patients in southern Appalachia." Medical Care 15(December):1004-1013.

Sackett, D.L., W.O. Spitzer, M. Gent and R.S. Roberts

1974 "The Burlington randomized trial of the nurse practitioners: health outcomes of patients." Annals of Internal Medicine 80(2):137-142.

Sox, Harold C., Jr.

1978 "Does the practice of medicine require a medical degree?" Archives of Internal Medicine 138 (February) : 199-200.

Spitzer, W.O., E.D. Sackett, J.C. Sibley, R.S. Roberts, M. Gent, D.J. Kergen, B.C. Hackett and A. Olynick

1974 "The Burlington randomized trial of the nurse practitioner." New England Journal of Medicine 290:251.

Storms, Doris M. and John G. Fox

1979 'The public's view of physicians' assistants and nurse practitioners: a survey of Baltimore urban residents." Medical Care 17(May):526-535.

Suchman, Edward A.

1965 "Social patterns of illness and medical care." Journal of Health and Human Behavior 6(Fall): 115-128.

Svarstad, Bonnie L.

1976 "Physician-patient communication and patient conformity with medical advice." Pp. 220-238 in David Mechanic (ed.), The Growth of Bureaucratic Medicine. New York: Wiley-Interscience. 
Thomas, Lewis

1977 "On the science and technology of medicine." Daedalus 106(Winter):35-47.

Tompkins, Richard, Robert Wood, Barry Wolcott, B. Timothy Walsh

1977 "The effectiveness and cost of acute respiratory illness medical care provided by physicians and algorithm-assisted physicians' assistants." Medical Care 15(December) : 991-1003.

Zyzanski, S.J., B.S. Hulka and J.C. Cassel

1974 "Scale for the measurement of 'satisfaction' with medical care: modifications in content, format and scoring." Medical Care 12:611-20. 